\title{
PROSPEK PEMBELAJARAN AQIDAH AKHLAK MENGGUNAKAN MODEL CONTEXTUAL TEACHING AND LEARNING DI SEKOLAH DASAR
}

\author{
Zunaidi M Rasid Harahap ${ }^{1^{*}}$ \\ 1*SD Muhammadiyah Purbayan, Yogyakarta, Indonesia.
}

\author{
Keyword: Learning \\ Aqidah Akhlak, \\ Contextual Teaching \\ and Learning \\ (CTL), Aqidah \\ Akhlak
}

\begin{abstract}
The purpose of this study was to describe the prospects for learning Aqidah Akhlak through the Contextual Teaching Learning (CTL) model in schools. The research method that has been carried out is descriptive qualitative research method, data is collected using documentation techniques, interview techniques, and observation. The data analysis technique is done by collecting data, reducing data, categorizing the data, describing the research findings, and making conclusions. The results showed that learning Aqidah Akhlak in Al-Islam subjects at SD Muhammadiyah could be done by teachers using the CTL learning model. The learning model with this approach is able to increase students' understanding of the meaning of discussions about belief, faith, morality, and character. With this method the benefits obtained are that students are able to explain, present, read well, memorize, and demonstrate good knowledge and behavior according to learning objectives. The CTL model can be used as an approach to the process of internalizing Islamic values in learning Aqidah Akhlak.
\end{abstract}

\section{ABSTRAK}

Tujuan dari penelitian ini adalah untuk mendeskripsikan prospek pembelajaran Aqidah Akhlak melalui model Contextual Teaching Learning (CTL) di sekolah. Metode penelitian yang penelitian yang telah dilakukan ialah metode penelitian deskriptif kualitatif, data dikumpulkan dengan teknik dokumentasi, teknik wawancara, dan observasi. Teknik analisis data dilakukan dengan mengumpulkan data, mereduksi data, mengkategorikan data, mendiskripsikan hasil temuan penelitian, dan membuat kesimpulan. Hasil penelitian menunjukkan bahwa pembelajaran Aqidah Akhlak dalam mata pelajaran Al-Islam di SD Muhammadiyah dapat dilakukan oleh guru dengan menggunakan model pembelajaran $C T L$. Model pembelajarandengan pendekatan ini mampu meningkatkan pemahaman siswa terhadap makna dari pembahasan-pembahasan tentang keyakinan, keimanan, akhlaq, dan budi pekerti. Dengan metode ini manfaat yang didapatkan adalah siswa mampu menjelaskan, mempresentasikan, membaca dengan baik, menghafal, dan mendemonstrasikan pengetahuan dan prilaku yang baik sesuai tujuan pembelajaran. Model CTL dapat dijadikan sebagai pendekatan pada proses internalisasi nilai-nilai Islam dalam pembelajaran Aqidah Akhlak.

\section{PENDAHULUAN}

Pembelajaran Aqidah Akhlak merupakan salah satu mata pelajaran pendidikan agama Islam yang mengandung pengertian pengetahuan pendidikan dan penghayatan tentang keyakinan atau kepercayaan dalam Islam yang menetap dan melekat dalam hati yang berfungsi sebagai pandangan 
hidup, perkataan dan amal perbuatan siswa dalam segala aspek kehidupannya sehari-hari. Pembelajaran aqiadah akhlak memberikan pengajaran tentang tata nilai yang mengatur hubungan antara manusia dengan tuhan, mengatur hubungan dengan sesama manusia, mengatur hubungan dengan lingkungan dan mengatur dirinya sendiri (Siska Fitri Yanti, 2017: 5).

Pendidikan Aqidah Akhlak memiliki peranan penting dalam membentuk tingkah laku siswa, sebab dengan pendidikan Aqidah Akhlak, siswa tidak hanya diarahkan kepada pencapaian kebahagiaan hidup di dunia saja, tetapi juga untuk kebahagiaan hidup di akhirat. Dengan pendidikan Aqidah Akhlak siswa diarahkan mencapai keseimbangan antara kemajuan lahiriah dan batiniah, keseimbangan hubungan antara manusia dalam kehidupan sosial dan lingkungannya, juga hubungan manusia dengan Tuhannya.

Dalam penerapan materi pembelajaran guru harus memperhatikan potensi siswa, relevansi dengan karakteristik daerah, tingkat perkembangan fisik, intlektual, emosional, sosial, dan spritual siswa, kebermanfaatan bagi siswa, struktur keilmuan, aktualitas, kedalaman, dan keluasan materi pembelajaran, relevansi dengan kebutuhan siswa dan tuntutan lingkungan dan alokasi waktu (Fitri Erning Kurniawati, 2015: 376).

Kemampuan guru merupakan faktor pertama yang dapat mempengaruhi keberhasilan sosialisasi dan pembelajaran. Guru yang memiliki kemampuan tinggi akan bersikap kreatif dan inovatif yang selamanya akan mencoba dan mencoba menerapkan berbagai penemuan baru yang dianggap lebih baik untuk pembelajaran siswa. Suatu asumsi bahwa peningkatan mutu pembelajaran di sekolah dapat dicapai melalui peningkatan mutu sumber daya manusia (guru dan tenaga kependidikan lainnya) (Siska Fitri Yanti, 2017: 5).

Pada proses pembelajaran guru juga tidak menggunakan media yang menarik. Guru hanya memanfaatkan papan tulis dan buku ajar. Hal tersebutlah yang menjadi salah satu penyebab ketidakaktifan siswa di kelas. Padahal seharusnya seorang guru mampu mekonstruk pembelajaran dengan baik agar siswa menjadi aktif dan semangat belajar (Muammar \& Suhartina, 2018: 177).

Materi Aqidah Akhlak sering disampaikan secara ekspositori. Namun guru dianggap sebagai sumber belajar satusatunya. Hal ini menyebabkan siswa kurang tertarik dan kurang aktif dalam pembelajaran Selain itu, siswa tampak bosan dengan model pembelajaran Aqidah Akhlak yang selama ini diterapkan. Demikian itu menunjukkan bahwa interaksi dan komunikasi yang terkait dengan keterlibatan siswa pada proses pembelajaran masih kurang.

Guru yang hebat itu bisa menyampaikan materi yang sulit dengan bahasa yang mudah difahami, salah satu caranya dengan menggunakan model pembelajaran yang selaras dengan materi yang disampaikan. Penerapan strategi dan model pembelajaran al-Islam (Aqidah Akhlak) yang dirasakan saat ini masih konversional dan menoton, sehingga materi al-Islam tidak efektif jika diajarakan secara konversional. Dengan demikian, keaktifan dan tanggung jawab peserta didik tidak tersalurkan secara optimal.

Melihat dari tujuan pembelajaran buku Al-Islam kelas V semester II bahwa siswa di tuntut harus mampu mejelaskan, mempersentasikan, membaca, mengahafal, menerangkan, dan 
menunjukkan. Dengan tujuan pembelajaran yang ini, tidak sangat susah atau bahkan mustahil akan tercapai jika guru hanya menggunakan menggunakan metode ceramah, sebagaimana yang dilakukan oleh guru mata pelajaran. Oleh sebab itu perlu adanya yang model pembelajran yang memjembatani agar tujuan tersebut tercapai.

Salah satu metode yang menyenangkan yang melibatkan kemampuan kognitif, afektif, dan sikomotorik siswa ialah metode Contextual Teaching and Learning (CTL). Pembelajaran CTL merupakan suatu peroses pendidikanyang holistik dan memiliki tujuan membantu peserta didik untuk memahami materi pelajaran yang dipelajarinya dengan mengaitkan materi tersebut dengan konteks kehidupan mereka sehari-hari (konteks pribadi, sosial dan kultural), peserta didik memiliki pengetahuan/keterampilan yang secara fleksibel dapat diterapkan dari suatu permasalahan kepermasalahan lainnya (Tatang Hidayat \& Syahidin, 2019: 120-121).

Berdasarkan latar belakang tersebut, peneliti berasumsi dengan menggunakan model CTL dalam pembelajaran Aqidah Akhlak pada mata pelajaran Al-Islam dapat memberikan kontribusi yaitu mendorong motivasi belajar yang mampu meningkatkan daya nalar dan logika peserta didik dalam merespon kondisi lingkungan dan sekitarnya. Peneliti menawarkan model pembelajaran yang relevan dengan tujuan pembelajaran dan kondisi peserta didik yakni dengan menggunakan model pembelajaran CTL. Diharapkan akan terjalin susasana belajar yang menyenangkan, tidak membosankan, dan menggunakan berbagai sumber belajar, yang kemudian menjadikan peserta didik aktif, kritis, cekatan, dan responsif terhadap lingkungan sekitar. Guru pun akan dituntut untukkreatifinovatif dalam mengolah dan mengelaborasi pembelajaran.

\section{METODE PENELITIAN}

Penelitian ini merupakan jenis penelitian kualitatif deskriptif. Penelitian kualitatif deskriptif merupakan jenis penelitian yang berupaya mendeskripsikan fenomena secara apa adanya. Teknik pengumpulan data menggunakan metode observasi, wawancara, dan dokumentasi. Metode observasi digunakan peneliti untuk mendapatkan gambaran suasana lingkungan penelitian. Metode wawancara digunakan peneliti untuk mendapatkan data-data perspektif guru tentang pembelajaran Aqidah Akhlak menggunakan model CTL. Adapun dokumentasi digunakan oleh peneliti untuk mendapatkan gambaran karakter bahan ajar Al-Islam tentang Aqidah Akhlak yang dapat memanfaatkan model CTL.

Subjek pada penelitian ini adalah guru dan bahan ajar Al-Islam tentang Aqidah Akhlak di SD Muhammadiyah. Objek pada penelitian ini adalah model CTL yang diimplementasikan di sekolah. Teknik analisis data yang dilakukan adalah pengumpulan data, reduksi data, kategori data, deskripsi hasil dan pengambilan kesimpulan. 


\section{HASIL DAN PEMBAHASAN}

\subsection{Pengertaian Aqidah dan Akhlak}

Aqidah menurut bahasa, berasal dari kata $د \dot{\theta} \quad \vartheta \varepsilon^{\circ} \varepsilon \quad$ yang artinya ikatan atau mengadakan

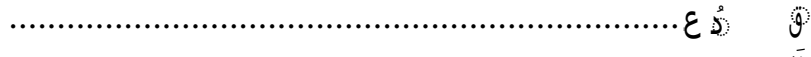

5

perjanjian. Sedangkang menurut syara' Aqidah adalah keimanan (kepercayaan) yang mantap kedapa Allah, para malaikat-Nya, kitab-kitab-Nya, para rasul-Nya, hari akhir seta kepercayaan kepada qadar (takdir) yang baik maupun yang buruk (Darwis Abu Ubaidah, 2008: 9). Aqidah akhlak merupakan salah satu materi pendidikan agama Islam. Dalam materi aqidah akhlak di sana dijelaskan tentang dasar-dasar keimanan terhadap Allah SWT. juga nilai-nilai tauhid lainnya. Kemudian dalam materi akhlak di sana dikaji dan dijelaskan tentang konsep akhlak serta nilai-nilai yang terkandung di dalamnya (Nurul Hidayati Rofiyah, 2016: 56).

Pembelajaran Aqidah Akhlak merupakan salah satu mata pelajaran PAI yang menekankan pada kemampuan memahami dan mempertahankan keyakinan atau keimanan yang benar, mempelajari bagaimana tata cara berinteraksi dengan manusia (habluminannas) serta hubungan manusia dengan sang khalik (habluminallah). Dengan ini diharapkan siswa tertanam keteladanan dan pembiasaan dalam mengamalkan akhlak terpuji dan adab islami melalui pemberian contohcontoh perilaku dan cara mengamalkannya dalam kehidupan sehari-hari (Fitri Erning Kurniawati, 2015: 369).

Maka dari itu, materi pendidikan Aqidah Akhlak bukan hanya mengajarkan pengetahuan tentang agama, akan tetapi bagaimana membentuk kepribadian siswa agar memiliki keimanan dan ketakwaan yang kuat dan kehidupanya dihiasi dengan akhlak yang mulia dimanapun merekaberada. Ada dua ciri pendekatan sistem pembelajaran, yaitu:

a. Pendekatan sistem merupakan suatu pendekatan tertentu yang mengarah ke proses belajar mengajar. Proses belajar mengajar adalah suatu penataan yang memungkinkan guru dan siswa berinteraksi satu sama lain untuk memberi kemudahan bagi siswa belajar.

b. Penggunaan metodologi khusus untuk mendesain sistem pembelajaran. Metodologi khusus itu terdiri atas prosedur sistemik perencanaan, perancangan, pelaksanaan, dan penilaian keseluruhan proses belajar mengajar. Kegiatan tersebut diarahkan untuk mencapai tujuan-tujuankhusus dan didasarkan pada penelitian dalam belajar dan komunikasi. Penerapan metodologi tersebut akan menghasilkan suatu sistem belajar yang memanfaatkan sumber manusiawi dan nonmanusiawi secara eisien dan efektif. Dengan demikian, pendekatan sistem merupakan suatu panduan dalam rangka perencanaan dan penyelenggaraan pengajaran (Nurul Hidayati Rofiyah, 2016: 56).

\subsection{Pembelajaran Aqidah Akhlak}

Proses pembelajaran merupakan serangkaian kegiatan yang dilaksanakan oleh guru danpeserta didik dengan memanfaatkan sarana yang tersedia untuk mencapai hasil belajar yang 
optimal. Proses pembelajaran dapat terlaksana dengan baik apabila terjadi interaksi antara guru dan peserta didik, antara sesama peserta didik atau dengan sumber belajar lainnya. Dengan kata lain proses pembelajaran berlangsnug efektif apabila guru memiliki kemampuan untuk menciptakan suasana kelas yang mendukung efektivitas pembelajaran agar tercipta suasana belajar yang nyaman, kondusif, komunikatif dan dinamis (Sufiani, 2017: 129).

Secara umum pembelajaran Aqidah Akhlak mengarah kepada pemahaman dan penghayatan isi yang terkandung dalam Akidah Akhlak yang diharapkan dapat diwujudkan dalam kehidupan sehari-hari. Mata pelajaran Akidah Akhlak adalah salah satu mata pelajaran dalam rumpun Pendidikan Agama Islam yang mengandung makna sebagai pengetahuan, pemahaman dan penghayatan ajaran Islam sebagai pedoman hidup. Dengan demikian karakteristik mata pelajaran Aqidah Akhlak menekankan pada pengetahuan, pemahaman dan penghayatan terhadap pedoman hidup yang dapat dijadikan pola perilaku dalam kehidupan sehari-hari. Olehnya itu, dalam pembelajaran aqidah akhlak tidak hanya mengarah pada persoalan teoritis dalam aspek kognitif, tapi bermuara pula pada aspek afektif dan psikomotorik. Dalam pembelajaran Aqidah Akhlak terdapat tujuan yang hakiki yakni menanamkan dan meningkatkan keimanan serta mempertinggi kesadaran untuk berakhlak mulia sehingga peserta didik menjadi manusia yang beriman dan bertakwa kepada Allah SWT (Sufiani, 2017: 136).

Pembelajaran aqidah akhlak adalah upaya sadar dan terencana dalam menyiapkan peserta didik untuk mengenal, memahami, menghayati dan mengimani kepada Allah SWT dan merealisasikannya dalam perilaku akhlak mulia dalam kehidupan seharihari berdasarkan Qur'an dan hadits melalui kegiatan bimbingan, pengajaran, latihan, serta penggunaan pengalaman (Purniadi Putra, 2017: 151). Hal serupa diungkapkan oleh Hery Noer Aly dan Munzier bahwa orientasi akhlak keagamaan merupakan sesuatu yang asasi di dalam pendidikan Islam. Seruan agar berakhlak mulia, menjunjung tinggi hidayah dan berbudi pekerti luhur sebagaimana dimuat dalam al-Qur'an, hadits Rasulullah SAW dan sumber-sumber primer warisan budaya Islam melegitimasi keutamaan orientasi tersebut (Hery Noer Aly dan Munzier, 2008: 149).

Pembelajaran Aqidah Akhlak pada buku al-Islam kelas IV semester II di SD Muhammadiyah secara materi sangat bagus mulai dari paparan Aqidah (Asmaul Husna dan Iman Kepada Nabi dan Rasul) kemudian materi Akhlak (sabar, tawadhu', jujur, dan ikhlas). Peneliti melihat materi tidak akan tersalurkan ke siswa kalau guru hanya mengandalkan dengan satu metode. Meskipun berbicara tentang ketauhitan bukan berarti tidak bisa disampaikan melalui metode pembelajaran. salah satu metode pembelajaran yang peneliti tawarkan ialah metode CTL.

\subsection{Model Contextual Teaching and Learning (CTL)}

Pembelajaran kontesktual dibangun atas dasar teori dari Jhon Dewey, Piaget, Brunner dan yang lainnya. Resnik dan Hall menyatakan bahwa pengetahuan didasarkan pada kontruktism 
artinya anak yang membangun secara langsung pengetahuan tersebut melalui berbagai aktifitas. Berdasarkan hal tersebut maka penggunaan model belajar kontekstual didasarkan pada aktifitas anak, anak melakukan sendiri materi-materi yang disampaikan oleh guru disesuaikan dengankebutuhan anak. Anak membangun pengetahuan melalui aktifitas yang dipilih sendiri. Tindakan yang dilakukakan anak dalam bermain merupakan motivasi intrinsik. Tidak semua pengetahuan diperoleh anak dengan cara yang sama (2013: 95).

Pembelajaran dan pengajaran CTL adalah sebuah sistem belajar yang didasarkan pada filosofi bahwa siswa mampu menyerap pelajaran apabila mereka menangkap makna dalam materi akademis yang mereka terima, dan mereka mengkap makna dalam tugas-tugas sekolah jika merekabisa mengaitkan informasi baru dengan pengetahuan dan pengalaman yang mereka miliki sebelumnya (Elaini B Johnson,2010: 14)

Dapat disimpulkan dari beberapa pengertian diatas bahwa pembelajaran kontekstual adalah sebuah sistem yang merangsang otak siswa untuk menyusun pola-pola yang mewujudkan makna. Pembelajaran atau pengajaran kontekstual merupakan suatu proses pendidikan yang holistik dan bertujuan membantu siswa untuk memahami makna materi pelajaran yang dipelajarinya dengan mengkaitkan materi tersebut dengan konteks kehidupan mereka sehari-hari (konteks pribadi, sosial dan kultural), sehingga siswa memiliki pengetahuan atau keterampilan yang secara fleksibel dapat diterapkan (ditransfer) dari satu permasalahan atau konteks ke permasalahan/konteks lainnya (Sugeng Kurniawan, 2015: 80).

Tugas guru kelas kontekstual adalah membantu peserta didik mmencapai tujuannya, yakni lebih banyak bertujuan dengan strategi dari pada memberi imformasi. Tugas guru mengelola kelas sebagai sebuah tim yang bekerja bersama untuk menemukan sesuatu yang baru bagi anggota kelas (siswa). Pendekatan pembelajaran tersebut tidak bersifat doktrinal. Pendekatan pembelajaran kontekstual memiliki tujuh komponen utama. yang harus dilakuan dengan sungguh-sungguh oleh seorang pendidik dalam menyampaikan materi pembelajaran (Sugeng Kurniawan, 2015: 81-84).

Pembelajaran kontekstual didasari oleh pendekatan pembelajaran berbasis konstruktivisme, yaitu suatu proses menyusun pengetahuan baru dalam struktur kognitif peserta didik berdasarkan pengalaman peserta didik membangun pemahan sendiri, mengkonstruksi konsep aturan dan analisis sintesis. Pengalaman belajar yang dilakukan siswa adalah; 1) Menemukan atau inquiri, yaitu proses pembelajaran yang didasarkan pada usaha pencarian dan penemuan melalui proses berfikir secara sistematis seperti identifikasi, investigasi, hipotisis, konjektur, generalisasi, dan menemukan; 2) Bertanya atau Questioning, yaitu belajar hakikatnya adalah bertanya dan menjawab pertanyaan. Bertanya dapat dipandang sebagai sefleksi dari keingin tahuan setiap individu, sedangkan menjawab pertanyaan mencerminkan kemampuan seseorang dalam berpikir seperti eksplorasi,membimbing menuntun, mengarahkan, mengembangkan, evaluasi, dan generalisasi; 3) Masyarakat 
belajar atau Learning community mensarankan agar hasil pembelajaran diperoleh melalui kerja sama dengan orang lain.kerja sama itu dapat dilakukan dalam berbagai bentuk baik dalam kelompok belajar secara formal maupun dalam lingkungan yang terjadi secara alamiah; 4) Pemodelan atau Modelling, yaitu proses pembelajaran dengan memperagakan sesuatu sebagaicontoh yang dapat ditiru oleh setiap peserta didik. Misalnya pemusatan perhatian, motivasi, penyampaian konpetensitujuan, pengarahan petujuk; 5) Refleksi atau reflection, yaitu proses pengendapan pengalan yang telah dipelajari yang dilakukan dengan cara mengutrakan kembali peristiwa pembelajaran yang telah dilalui. Misalnya reviw, rangkuman dan tindak lanjut; dan 6) Penilaian yang sebenarnya atau Authentic assesment, yaitu proses yang dilakukan oleh guru untuk mengumpulkan informasi tentang perkembangan belajar yang dilakukan oleh siswa. Misalnyapenilaian selama proses dan sesudah pembelajaran, penlilaian setiap aktivitas usaha peserta didik (Tatang Hidayat \& Syahidin, 2019: 123).

Pembelajaran al-Islam mesti direncanakan dengan baik, supaya pembelajaran tidak hanya berdasarkankegiatan formal saja, tetapi ada nilai lebih dari itu semua,yakni ada nilai-nilai ilahiyah. Sasaran metode CTL hakikatnya bisa diimplementasikan dalam materi-mater al-Islam yang diajarkan disemua jengjang pendidikan mulai SD, SMP, dan SMA/sederajat. Terutama materimateri al-Islam memerlukan adanya studi lapangan dan pengalaman. Guru al-Islam mesti mebuat perencanaan pembelajaran yangselaras dengan tujuan pembelajaran al-Islam. Begitupun dengan pendekatan metode, strategi, tekhnik, taktik, dan model yang digunakan mesti selaras dengan materi yang ditawarkan (Tatang Hidayat \& Syahidin, 2019: 126-127).

\subsection{Pembelajaran Aqidah Akhlak dengan Pendekatan Kontekstual Learning}

CTL pada dasarnya dapat diterapkan dalam kurikulum apa saja, dan bidang apa saja, kelas yang bagaimanapus keadaannya (Trianto, 2008: 25-26). Kalau dikaitkan dengan Aqidah Akhlak metode CTL sangat cocok untuk di terapkan, namun tidak semua guru mengetahui metode tersebut. Sangat sering dijumpai penyampaian materi Aqidah Akhlak guru menggunakan selalu menggunakan metode ceramah, sehingga siswa merasa bosan dan kurang ketertarikan terhadap materi tersebut. Padahal sangat banyak metode belajar dalam penyampaian mata pelajaran Al- Islam, terutama metode CTL. Metode tersebut bisa lakukan di dalam kelas dan di luar kelas. Adapun aspek-aspek dari materi Aqidah Akhlak SD Muhammadiyah kelas IV pada semester 2 : Aspek Aqidah yaitu: mengenal nama-nama baik milik Allah SWT Asmaul Husna (Al-Ghaffar, Al- Qahhar, Ar-Razzaq, dan Al-Fattah). Dan Iman kepada Nabi dan Rasul. Apek Akhlak yaitu: Sabar, tawadhu, jujur, dan ikhlas terdiri atas keimanan kepada sifat wajib, mustahil dan jaiz Allah. Keimanan kepada kitab Allah, Rasul Allah, sifat-sifat dan mukjizatnya dan hari akhir. Kalau meteritersebut dijelaskan oleh guru hanya dengan menggunakan metode ceramah otomatis pembelajaran Aqidah Akhlak akan kurang diminati oleh siswa, karena materi tersebut bisa dikatakan materi yang 
cukup rumit, oleh sebab itu guru agama harusnya banyak mengetahui tentang menggunanaan metede pembelajaran terutama metode CTL.

Materi Aqidah Akhlak pada buku al-Islam kelas IV semester II (Asmaul Husna dan Iman kepada Nabi dan Rasul) dan Sabar, Tawadhu', Jujur dan Ikhlas. Aspek materi Aqidah: Al-Ghaffar artinya Maha Pengampun. Maha pengampun adalah sifat yang memperlihatkan kemuliaan dan menyembunyikan kehinaan. Al-Qahhaar artinya Maha perkasa. Dialah yang menjadi tempat tunduk bagi seluruh hamba-Nya. Al-Razzaaq artinya Maha pemberi rizky. Ialah sifat Allah yang menciptakan sarana memperoleh rizky. Al-Fattaah artinya Maha membuka. Maha membuka adalah sifat Allah yang menyebabkan segala sesuatu yang semula tertutup menjadi terbuka dan yang membimbing agar segala sesuatu yang semula tak jelas menjadi terjelaskan. Kemudian Imankepada Nabi dan Rasul: Nabi adalah seorang laki-laki yang diber wahyu oleh Allah lewat malaikat jibril untuk dirinya sendiri. Sedangkan rasul adalah seorang laki-laki yang diberi wahyu oleh Allah lewat malaikat jibril untuk dirinya sendiri dandisampaikan kepada ummatnya. Kemudian ciri-ciri Nabi dan Rasul, Sifat-sifat Nabi dan Rasul, Nabi penerima kitab, dan cara beriman kepada Nabidan rasul. Sedangkan aspek materi Akhlak: Sabar artinya menahan, menjegah atau mengekang.maksudnya menahan diri dari segala sesuatu yang tidak disukai karena mengharapridha Allah. Tawadhu artinya adalah rendah hati lawan dari sombong atau takabur. Jujur artinya adalah mengakui,berkata ataupun memberi informasi yang sesuai dengan apa yang benar-benar terjadi. Ikhlas artinya adalah melakukan amal ibadah dan perbuatan baik karena Allah SWT. Tanpapamrih dan bukan karena selain Allah SWT (Haedar Nasir, 2017/2018: 89-124).

Hasil wawancara dengan guru agama di SD muhammadiyah selaku pengampu mapelAqidah Akhlak bapak Alif Cahya menyatakan: pembelajaran Aqidah Akhlak selama ini masih menggunakan metode ceramah, karena karena pembelajaran tersebut menyangkut tentang ketauhitan ataupun keyakinan kepada Allah SWT. Namun kalau di bidang Akhlak guru pernah menggunakan metede diluar metode ceramah. Selain itu guru juga masih kekurangan memahami tertang berbagai metode. Dari penjelasan tersebut bisa disimpulkan bahwa kebanyakan guru agama selama ini dalam penyampaian materi (Aqidah Akhlak) masih bertahan dalam metode ceramah. Dengan CTL diharahapan mampu membuat peserta didik kerja sama dan saling membantu serta menjadikan peserta didik mampu berpikir keritis dalam menyelesaikan masalah yang diberikan. Materi Aqidah Akhlak meruakan salah satu materi yang diajarkan di kelas IV SD Muhammadiyah. Denga pembelajaran CTL peserta didik bisa belajar melalui keaktifan serta mengaitkan materi yangada didalam kelas dengan setuasi dunia nyata.

\section{KESIMPULAN}

Pembelajaran Aqidah Akhlak adalah pembelajaran yang sangat menarik dan bisa di sampaikan dengan berbagai metode. Metode pembelajaran kontestual sangat relevan untuk 
diimplementasikan pada pembelajaran Aqidah Akhlak sebagai upaya internalisasi nilai-nilai iman dan akhlaq mulia. Pembelajaran yang dilakukan dengan metode CTL dilakukan dengan banyak dan beragam aktifitas melibatkan peserta didik dengan mengkaitkan materi pelajaran dengan konteks kehidupan nyata. Guru Aqidah Akhlak diharapkan mampu mengembangkan pembelajaran dari model ceramah, kepada metode pembelajran CTL. Pembelajaran dengan CTL juga dapat dikembangkan dengan media pembelajaran berbasis audio visual yang menarik dan interaktif.

Buku Aqidah Akhlak di SD Muhammadiyah sudah sangat bagus. Demikian itu didasari bahwa nilai-nilai keimanan dan akhlak yang disampaikan pada buku tersebut relevan dan komunikatif untuk dipelajari dan diaktualisasikan oleh peserta didik. Bahan ajar yang baik membutuhkan pendekatan dan metode yang baik agar dapat ditangkap oleh peserta didik. Kesesuaian antara bahan ajar dengan pendekatan dan metode pembelajaran berdampak pada pencapaian tujuan pembelajaran dan tujuan pendidikan.

\section{REFERENSI}

Nurul, H. R. (2016). Desain Pengembangan Pembelajaran Akidah Akhlak Di Perguruan Tinggi. Jurnal Fenomena, vol. 8 no. 1

Siska, F. Y. (2017). Aqidah Learning Moral Influence On Student Behavior In Madrasah Aliyah Kampart Country East. Jurnal Jom Fisip, vol. 4 no. 1

Fitri, E. K. (2015). Pengembangan Bahan Ajar Aqidah Ahklak Di Madrasah Ibtidaiyah. Jurnal Penelitian, vol. 9 no. 2

Darwis, A. U. (2008). Panduan Aqidah AhluSunnah Wal Jamaah, (Jakarta:Pustaka Al-kautsar).

Sufiani. (2017). Efektivitas Pembelajaran Aqidah Akhlak Berbasis Manajemen Kelas. Jurnal AlTa'dib vol 10 no. 2

Hery., N. A., \& Munzier. (2008). Watak Pendidikan Islam, (Jakarta Utara: Friska Agung Insani).

Purniadi, P. (2017). Implementasi Pendidikan Karakter Dalam Pembelajaran Aqidah Akhlak. Jurnal Al-Bidayah, vol. 9 no. 2

Delfi., E. (2013). "Penerapan Model Pembelajaran Kontekstual Learning (CTL) Berbasis Centra Di Taman Kanak-kanak", Jurnal Pedagogi, vol. xii no. 2

Sugeng, K. (2015). Pembelajaran Pendidikan Agama Islam Berbasis Kontekstual. Jurnal Nur El Islam, vol. 2 no 1 
Tatang, H., \& Syahidin. (2019). Inovasi Pembelajaran Pendidikan Agama Islam Melalui Model Contextual Teaching And Learning Dalam Meningkatkan Taraf Berpikir Peserta Didik. Jurnal Pendidikan Agama Islam, vol. xvi, no.

Johnson, E, B. (2010). Contextual Teaching And Learning, Menjadikan Kegiatan Belajar-Mengajar Mengasikkan Dan Bermakna. (Penerjamah Ibnu Setiawan, Bandung: Kaifa)

Setyosari, P. (2013). Metode Penelitian Pengembangan. (Jakarta: Kencana Prenada Media)

Haedar, N. (2017/2018). Pendidikan Al-Islam SD Muhammadiyah. (Buku ajar Al-Islam: Aqidah Akhlak kelas IV) 